\title{
The Newest Sappho: Text, Apparatus Criticus, and Translation
}

\author{
Dirk Obbink
}

The text of Sappho exercised readers, scholars, and lovers long before her 'bright singing columns', $\lambda \varepsilon \cup \varkappa \alpha i ~ \varphi \theta \varepsilon \gamma o ́ \mu \varepsilon v \alpha \iota ~ \sigma \varepsilon \lambda i \delta \varepsilon \varsigma^{1}$, appeared in a Hellenistic edition on papyrus sometime in the third century BC. ${ }^{2}$ So vividly were her verses perceived as being orally performed and heard. ${ }^{3}$ By the Roman period, readers needed a commentary, together with an adequately corrected and annotated copy, in order to make sense of her poems. These contained the written words of the songs she had once sung, as they had been passed down, and corrected back into the dialect once spoken on the island of Lesbos, by some of the best scholars of the past centuries. Ancient editors, for example, even reinstated the letter digamma - a letter not used for over half a milleniumwhere it could be known from Homeric research and meter to have originally stood in her words, ${ }^{4}$ a practice that would be comparable to putting Runes back into Old English texts. Their texts were, of course, not perfect: but they knew the poems better (and had at their disposal far more of them to read) than we do today. As a result, in assessing the evidence of the ancient manuscripts of Sappho preserved on papyrus, a judicious attempt must be made to discern the places where their efforts succeeded, where they failed, and where modern erudition can be brought to bear on the text in order to isolate cases where more work, more understanding, is needed.

1 Posidippus, Epigr. 17 Gow and Page = 122 Austin and Bastianini (fictional epitaph for Doricha, but praising Sappho for singing about her), quoted by Athenaeus 13.69.

2 On the Alexandrian edition, see Liberman (2007).

3 Already Herodotus (2.135) cites something Sappho said in a song ( $\dot{\varepsilon} \nu \mu \varepsilon \dot{\varepsilon} \lambda \varepsilon i ̈$ C $\alpha \pi \varphi \omega \dot{\omega} \pi 0 \lambda \lambda \dot{\alpha}$

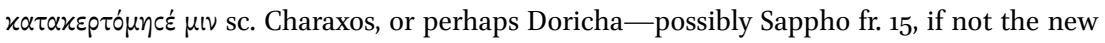
Brothers Song). Even earlier, we hear that Solon badly desired to learn by heart (apparently orally) a poem of hers that he had heard his young nephew sing 'over the wine' ( $\pi \alpha \rho \dot{\alpha} \pi$ ótov) movingly at a symposium ('Aelian' ap. Stob. Flor. 3.29 .50 vol. 3 p. 638 w.) —thus a reference to a text of Sappho's ante litteras.

4 A newly attested digamma appears in the new papyri, at Sappho fr. 5.3.

(C) DIRK OBBINK, 2016 | DOI: 10.1163/9789004314832_003

This is an open access chapter distributed under the terms of the Creative Commons Attribution-

Noncommercial 3.o Unported (CC-BY-NC 3.0) License. 
The new fragments published for the first time in 2014 all come from Sappho's first Book, in what turns out to have been an alphabetically ordered edition by incipit or first letter of first word, from the section (about 4-5 ancient columns or modern pages' worth) containing poems beginning with ' $O$ ' and ' $\Pi$ '. Remarkably, four out of the six previously published papyri of Sappho Book 1 come from this section, and so fortuitously overlap with the new fragments, and aided substantially in their identification. All the papyri range from the late first to the early third centuries AD, the hey-day of Roman book-production. ${ }^{5}$ All are professionally produced, written in up-scale bookhands for legibility, and have been corrected and equipped by editors with signs and annotations as aids to the reader. They were meant to be read, and to provide the best text that money could buy of a composer who had lived seven hundred years earlier and who may not have committed any of her songs to writing herself.

The present edition of ten of these fragmentary poems does not attempt to solve all problems, or even to document thoroughly the entire scholarly record of work on the text of the poems of Sappho already known among the new fragments. Rather, following the model of editions previously produced for volumes of collected essays on the new papyri of Simonides' Elegies ${ }^{6}$ and the New Cologne papyrus of Sappho, ${ }^{7}$ it is intended to provide a working text for referencing and discussing the poems, amalgamating the existing manuscript witnesses and comparanda in the secondary tradition, and documenting work on the relevant parts of Sappho's text since the most recent group of new fragments (the 'Newest Sappho') were published in 2014. ${ }^{8}$

Effort has in the first instance been expended on the papyri themselves, in particular on what the new ones have to add to the old ones with which they connect or otherwise relate. For example, for some of the fragments below, as many as four separate papyrus manuscripts contributed to the textual reconstruction of a single line-without any actual physical connection or overlap between any of them (e.g. Sappho fr. 5.15-20). In other cases, there was useful overlap, but occasionally frustratingly different readings from the overlapping witnesses (e.g. frs. 9.6, 17.3-4). Secondly, an attempt has been made to consider and document all viable proposals for the constitution of the text, and to print

5 Only two papyri of Sappho Book 1 do not overlap with the new fragments: P. Oxy. 2288, containing Sappho fr. 1 from the 3 rd c. AD which probably stood at the beginning of Book 1, and P. Oxy. 424 containing Sappho fr. 3; only one manuscript witness of Book 1 is earlier: the Florentine ostracon containing Sappho fr. 2 from the 2nd c. BC; P. Berol. inv. 5006, containing Sappho frs. $3^{-4}$ is a 7 th c. AD parchment that is practically a Mediaeval manuscript.

6 Boedeker and Sider (2001).

7 Greene and Skinner (2009).

8 Obbink (2014b); Burris, Fish, and Obbink (2014). 
only what seemed reasonably certain, while relegating less promising proposals to the apparatus criticus. There, competing proposals are usually ranked in descending order of persuasiveness, and supporting comparanda are added where relevant for assessing the strength of the argument for their adoption into the text. In cases where proposals seemed to be on the same evidential footing, they are ranked in chronological order of publication. Readings, supplements, or reconstructions impossible and physically at odds with the evidence of the papyrus manuscripts are omitted from consideration and, in general, mention. Passages left unrestored in the text are generally those that would benefit from further study and consideration before committing to a reading or restoration: thus, blanks in the text isolate areas where there is progress on and understanding of the text yet to be made. However, in a few places (for example, Sappho fr. 9), the restoration of the text ventures out on a limb for heuristic or suggestive purposes, to suggest the run of thought exempli gratia, or the shape of a poem or its argument, in the interest of encouraging further effort on what might otherwise seem like unpromising ground. The benefit of such conjectural restorations can be seen from the fact that the first of the new fragments to be identified among the Green papyri (Sappho fr. 5 ) was achieved by means of a search of the TLG corpus on sequences of letters in the papyrus that were not anywhere extant previously in any manuscript or quotation, but had been conjecturally restored by F. Blass in 1899 and printed as accepted restorations in modern editions of Sappho. The hope that further discoveries and connections one day will be made in this way, strongly advises to proceed in this careful if painstaking way towards the future text of Sappho.

\section{The Papyri}

$\Pi^{1}$ PSI 123 (late 1st c. AD papyrus roll, Biblioteca Medicea Laurenziana, Florence)

$\Pi^{2 a}$ P. Oxy. 1231 (2nd c. AD papyrus roll, Bodleian Library, Oxford: MS. Gr. class. c. $76(\mathrm{P}) 1-2)$

$\Pi^{2 b}$ P. Oxy. 2166 (a) 1 [additional fragment of $\Pi^{2 a}$ ]

$\Pi^{2 \mathrm{c}}$ P. Oxy. vol. 21, p. 122 [additional fragment of $\Pi^{2 \mathrm{a}}$ ]

$\Pi^{3}$ P. Oxy. 2289 (late 2nd c. AD papyrus roll, Sackler Library, Oxford)

$\Pi^{4}$ P. Oxy. 7 (early 3 rd c. AD papyrus roll, British Library, London: inv. 739)

$\Pi^{5 a}$ P. GC (early 3 rd c. AD papyrus roll, Green Collection (= GC), Oklahoma City: inv. 105)

$\Pi^{5 b}$ P. Sapph. Obbink (privately owned, formerly Robinson Collection, University of Mississippi USA) [additional fragment of $\Pi^{5 a}$ ] 


\section{Abbreviations}

$\left[\Pi^{1}\right]$

$\bigotimes$

Benelli

BF

BFO

Bowie

Di Benedetto

Diehl

Diels

Ferrari

Fränkel

Grenfell and Hunt

Hunt

Lardinois

Liberman

Lidov 2004

Lidov $^{1}$

Lidov $^{2}$

Lobel $A \mu$

Lobel $\Sigma \mu$

Martinelli Tempesta

Marzullo

Milne

Nagy

Neri

Obbink

Pfeijffer

Prodi

Schlesier

Schubart

Snell

Theander

West

Wilamowitz ${ }^{1}$

Wilamowitz $^{2}$ papyrus $\Pi^{1}$ does not preserve the text at this point beginning or end of poem marked in papyrus

Benelli (2015)

Burris and Fish (2014)

Burris, Fish, and Obbink (2014)

Bowie, this volume

V. Di Benedetto in Di Benedetto and Ferrari (1987)

Diehl (1917)

Diels (1898)

Ferrari (2014)

Fränkel (1928)

Grenfell and Hunt (1898)

Hunt (1914)

Lardinois, this volume

Liberman (2014)

Lidov (2004)

Lidov, ch. 3, this volume

Lidov, ch. 19, this volume

Lobel (1927)

Lobel (1925)

Martinelli Tempesta (1999)

Marzullo (1958)

Milne (1933)

Nagy, this volume

Neri (2014)

Obbink (2014b)

Pfeijffer (2000)

E. Prodi by private communication

Schlesier, this volume

Schubart (1948)

Snell (1944)

Theander (1934)

West (2014)

Wilamowitz (1898)

Wilamowitz (1914) 


\section{The Poems (in the original order of Sappho Book 1)}

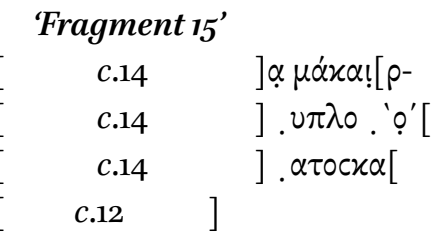

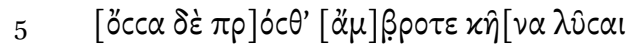

$[\ldots . . ..] \alpha \tau \alpha \iota c(). v \varepsilon \mu[--\smile-x$

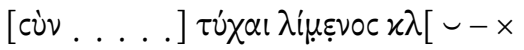

$\left[\begin{array}{lll} & c .11\end{array}\right]$.

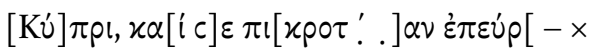

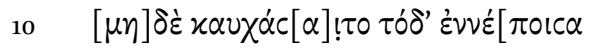

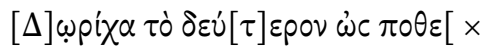

$[\ldots]$. . .]ероv $\hat{\eta} \lambda \theta \varepsilon .[\otimes]$

Sources: $\Pi^{2 a}$ (fr. 1 col. i + fr. 3) incipit in 'o'? $0-4$ stanzas missing? $1 \mu \alpha \dot{x} x$ ! [p $\alpha$

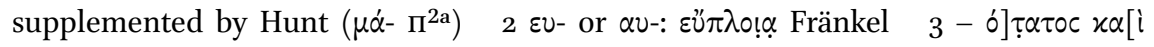

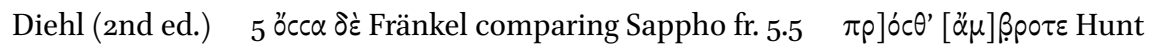

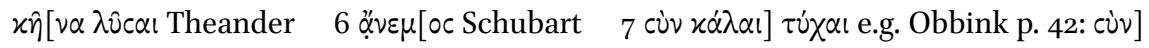

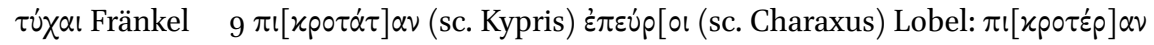

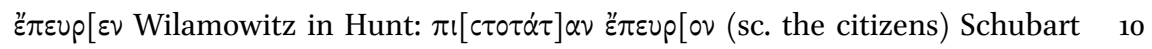

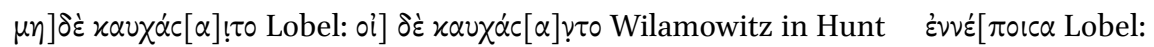

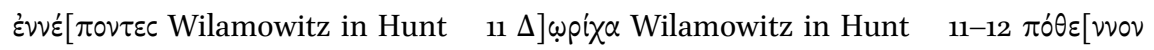

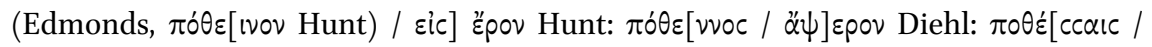
$\ddot{\alpha} \psi] \varepsilon \rho \circ \nu$ tentatively Voigt app. crit. ad loc. 12 घic] हैpov suits the space better than

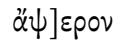

\section{'Fragment 16 '}

[Q]

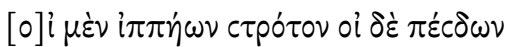

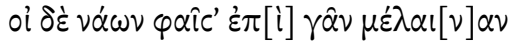

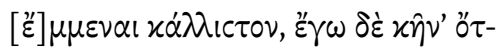

$\tau \omega \tau \iota c$ हैp $\alpha \tau \alpha l$.

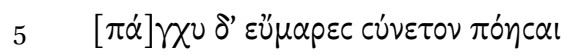

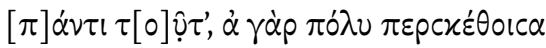

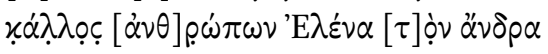

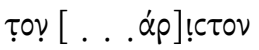




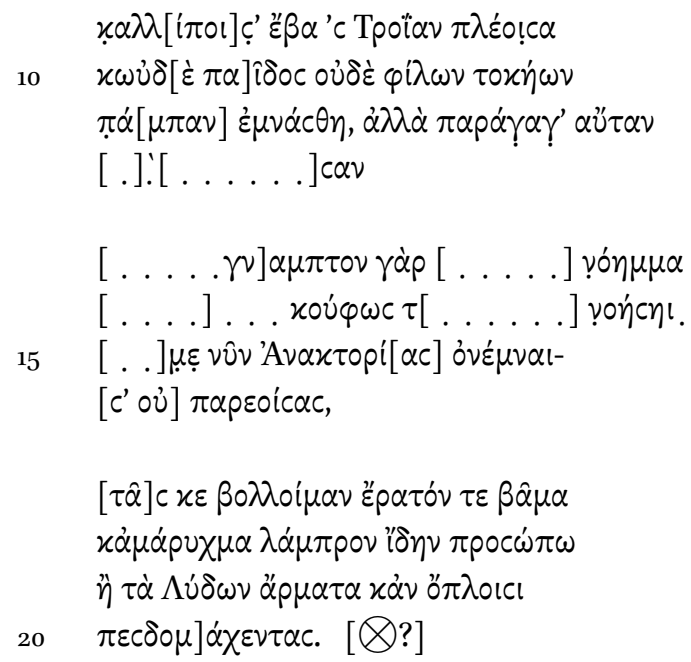

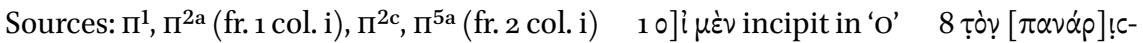

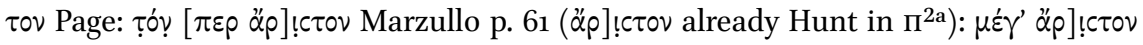
Gallavotti in Voigt comparing Hom. Il. 2.768, Theocr. 7.100 etc. $11 \pi \dot{\alpha}[\mu \pi \alpha \nu$ Theander

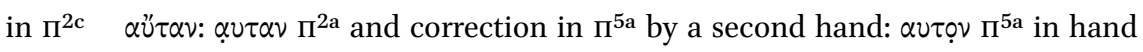
of the main scribe 12 ].'[ (the grave accent alone is preserved, but nothing of the letter that it stood over) $\Pi^{2 \mathrm{c}}:\left[\Pi^{1} \Pi^{2 \mathrm{a}} \Pi^{5 \mathrm{a}}\right]$, i.e. a 'warning' grave accent placed over first vowel of a dipthong, as often; perhaps $x] \dot{\omega}[v$, to be read as $\varkappa \omega \nu ่ \varkappa$ (Obbink) or $\varkappa \omega \nu \dot{\delta}$ '

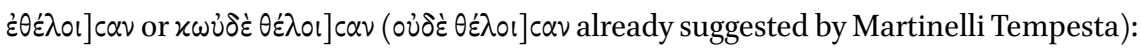

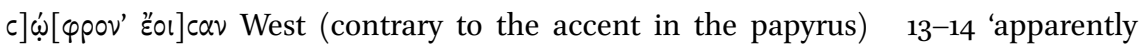
contained a general reflection on the weakness of human nature' Hunt perhaps

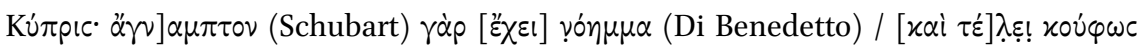

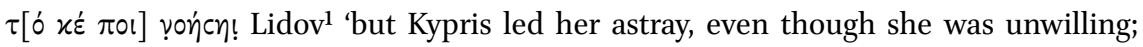
for she (sc. Kypris) has an unyielding mind and accomplishes easily whatever she

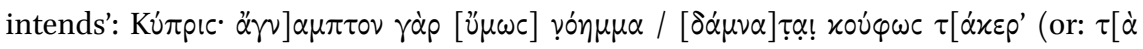

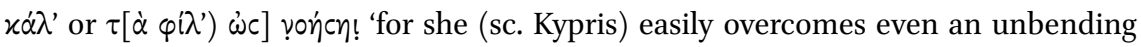
mind so that it thinks melting thoughts' (i.e. 'sets its thoughts on an object of desire')

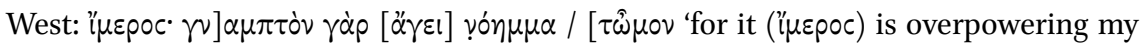
own malleable resolve' BF, cf. $\mathrm{N}\left(\left\llcorner\alpha \alpha^{\prime} \nu \omega \rho\right) \tau \omega \mu\right.$ ov $\Pi^{1}$ in left margin next to Sappho fr. 17.1, probably annotation of an intended correction or substituted reading in a line to its left in the preceding column, corresponding to about the level of this line i.e. Sappho

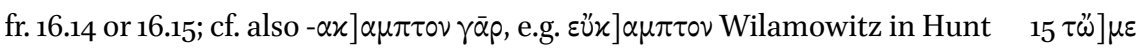
'which now puts me in mind' Lidov' (by private communication, and subsequently West): $\left.\tau \delta^{\prime}\right] \mu \varepsilon$ already Pfeijffer: $\left.x \alpha ̋\right] \mu \varepsilon$ Lobel, $\Sigma \mu \quad$ óv-correction by modern editors: $\alpha \nu$ $\Pi^{2 \mathrm{a}}:\left[\Pi^{5 \mathrm{a}}\right] \quad-\mu \nu \alpha \iota \Pi^{5 \mathrm{a}}$, correction in margin $\Pi^{2 \mathrm{a}}: \mu \nu \alpha \Pi^{2 \mathrm{a}} \quad 17 \chi \varepsilon$ correction by Hunt: $\tau \varepsilon$ $\Pi^{2 \mathrm{a}}:\left[\Pi^{1} \Pi^{2 \mathrm{a}} \Pi^{2 \mathrm{c}} \Pi^{5 \mathrm{a}}\right]$ 


\section{'Fragment $16 a^{\prime}$ [ continuing Line-Numeration of Fragment 16 in Parentheses] \\ $[\otimes ?]$}

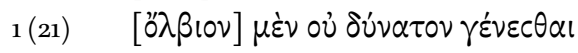

$\left[\pi \alpha^{\prime} \mu \pi\right] \alpha \nu \alpha^{\prime \prime} \nu \theta \rho \omega \pi[0 \nu \cdot \pi] \varepsilon \delta \delta^{\prime} \chi \eta \nu \delta^{\prime} \alpha^{\prime} \rho \alpha c \theta \alpha l$

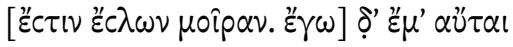

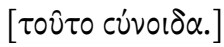

[2-4 stanzas missing]

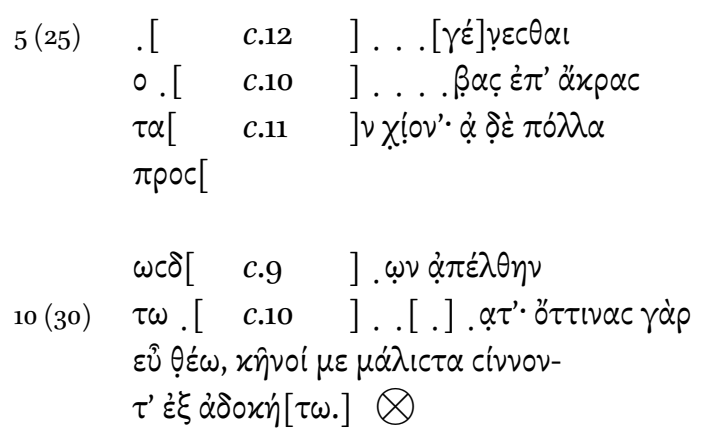

Sources: $\Pi^{1}, \Pi^{2 a}$ (fr. 1 coll. i-ii), $\Pi^{5 a}$ (fr. 2 coll. i-ii) $1-4$ possibly a continuation of Sappho fr. 161 (21) incipit in 'o'? e.g. ob $\lambda \beta 10 v]$ (-olc] Snell) $\mu \dot{\varepsilon} \nu$ Milne (NB there is no trace

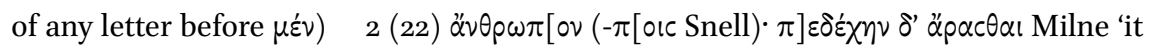
is not possible for a human being to be completely fortunate; but one may pray ..., cf.

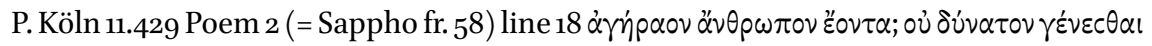

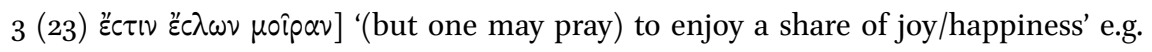

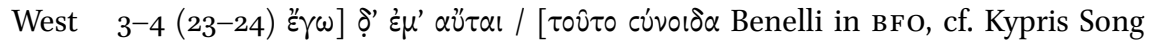

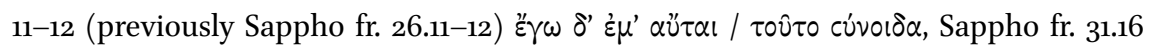

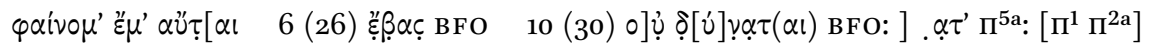

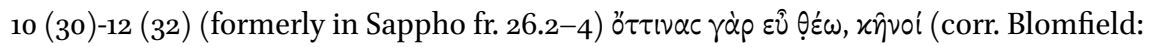

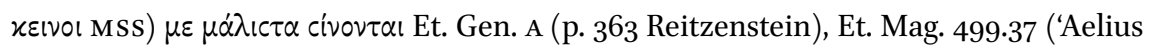

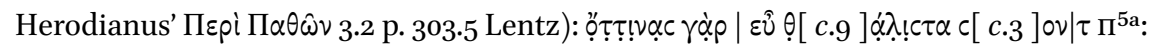

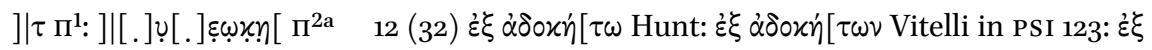

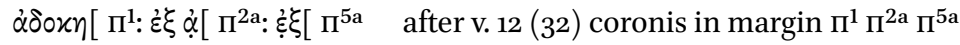

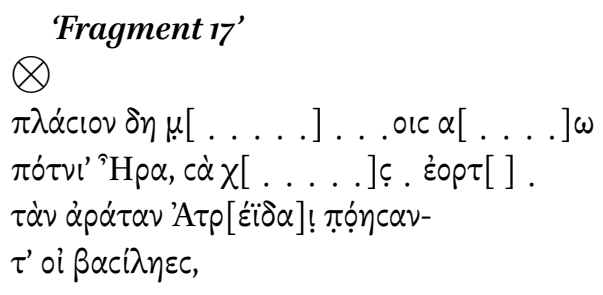




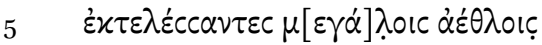

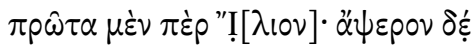

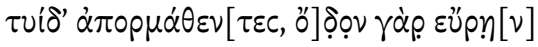

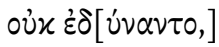

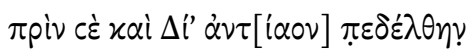

10

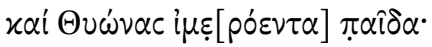

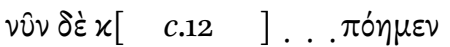

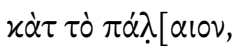

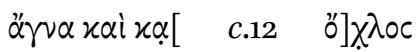

$\pi \alpha p \theta \varepsilon\left[\begin{array}{lll}\nu \omega \nu & c .12 \quad \gamma & \gamma\end{array}\right] \nu \alpha i x \omega \nu$

$15 \alpha \dot{\alpha \mu \varphi ı . ~[~}$

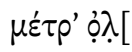

$\pi \alpha c[$

.[ .] . $v \lambda \lambda[$

$\varepsilon^{\prime} \mu \mu \varepsilon v \alpha[\llcorner$

20

$\left[{ }^{\top} \mathrm{H}\right] \rho^{\prime} \dot{\alpha} \pi^{\prime} i x \varepsilon[c \theta \alpha \mathrm{s.}] \otimes$

Sources: $\Pi^{1}, \Pi^{2 a}$ (fr. 1 col. ii), $\Pi^{2 b}, \Pi^{3}$ (fr. 9), $\Pi^{5 a}$ (fr. 2 col. ii) $\quad 1-2 \pi \lambda \alpha^{2} c 10 v \delta \dot{\eta}$ (incipit in

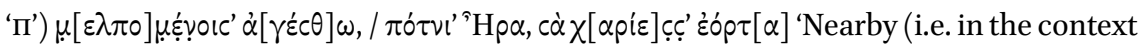
of this song/performance) let your charming festival be celebrated by (or with or for)

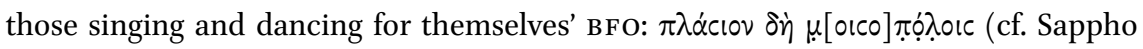

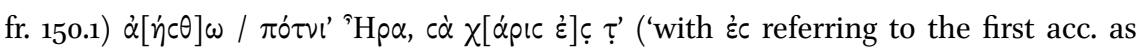
well') $\dot{c} \rho \tau[\alpha]$ ? 'Nearby let your favour blow towards the attendants of the Muses, and

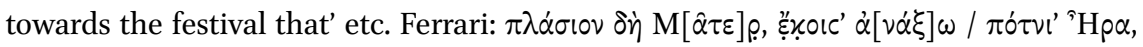

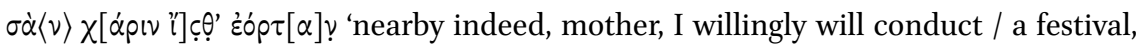
be certain, Lady Hera, for your sake' (cf. Alcaeus fr. 129.7 and Alcman fr. 56.2 , and for $\alpha \nu$ - instead of Lesbian o $v$-, see Sappho fr. 16.15 with app. crit. ad loc. above) Lidov ${ }^{2} \quad 2$

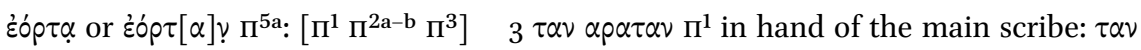
$\alpha \rho \alpha \tau\left[\Pi^{2 a}: \tau \alpha \nu \alpha\left[\Pi^{5 a}: \tau \alpha \nu \varepsilon \rho \alpha \check{\tau} \tau \nu\right.\right.$ in a second hand in $\Pi^{1}$ contra metrum $\quad \alpha \tau \rho\left[\Pi^{1:}\left[\Pi^{2 a-b}\right.\right.$

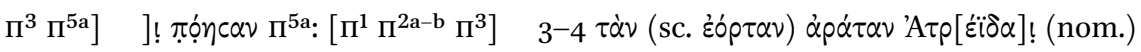
$\pi \circ \varphi^{\prime} c \alpha v / \tau$ ' oi $\beta \alpha c i \lambda \eta \varepsilon c$ 'which (festival) the Atreids, the leaders, hoped ("auspicarono") for themselves' Neri following the articulation suggested before the new fragment by

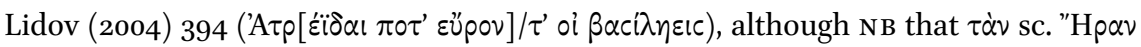
as in Hunt and editors following would still be possible, 'whom (sc. Hera) ... they

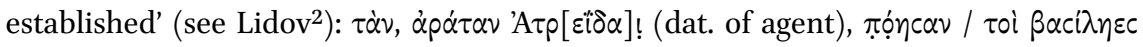
'which (festival), prayed for/vowed by the Atreid (sc. Menelaus, $O d$. 3.169-172), those

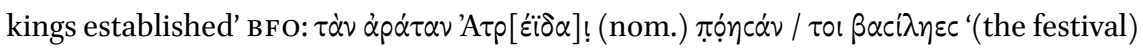


that the kings, Atreids, made desired by (or desirable to) you' Ferrari: 'the Atreidai ... established it in fulfilment of a vow' West 4 accent as placed in $\Pi^{5 a}$ marks word division: $\tau 0$ I is 'an article or demonstrative pronoun' BFO: ' $\tau \circ \mathrm{l}$ is the enclitic pronoun "for you"' West: $\tau$ o' is the non-enclitic 'emphatic personal pronoun' (supported by the accent as placed in $\Pi^{5 a}$ ) Nagy: perhaps $\tau$ oi should be emended to coí (see Apollonius

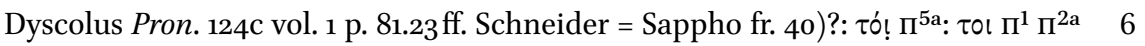

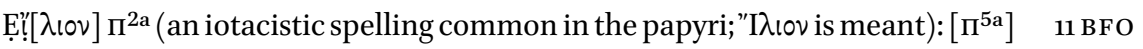

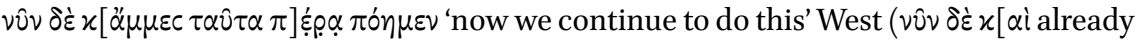

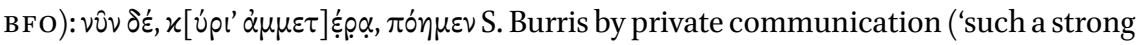
direct address would help signal the transition out of the mythical narrative back into the main discursive level of prayer') ] . . , $\alpha, \varepsilon$, or $\circ$ followed by $\rho \alpha$ or $\rho ı$ or $\beta l 12$

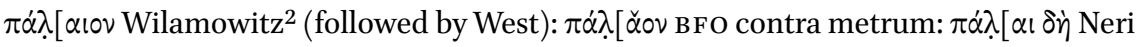

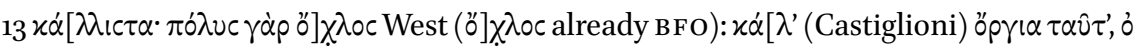

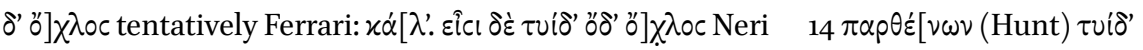

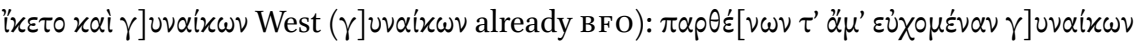

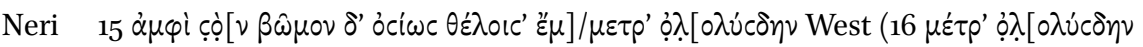

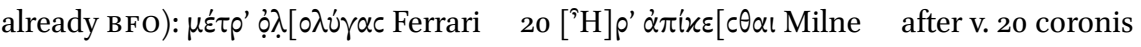
in margin $\Pi^{2 \mathrm{a}}:\left[\Pi^{1} \Pi^{5 \mathrm{a}}\right]$

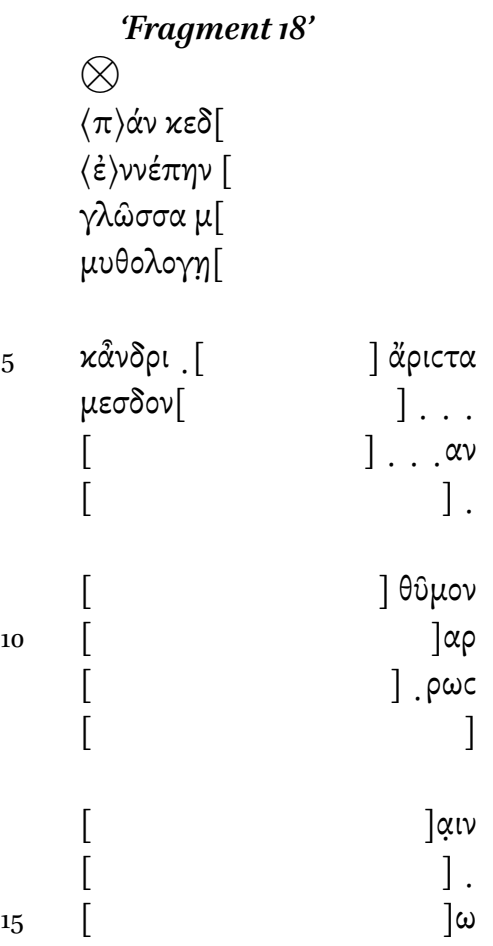


Sources: $\Pi^{2 a}$ (fr. 1 col. ii), $\Pi^{5 a}$ (fr. 3 col. i) $1-2$ supplemented by Lobel, $\Sigma \mu \quad 1\langle\pi\rangle \alpha^{\prime} \nu$

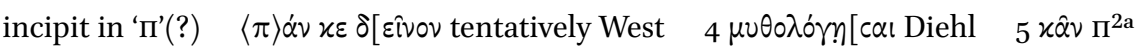
after v. $15,4-6$ stanzas missing before fr. 18a

\section{'Fragment 18a'}

. ..... [

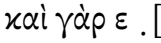

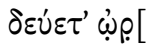

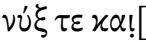

$5 \quad . .0$.... . [

$. \alpha c \omega . .[$

$. \alpha . \alpha \ldots[$

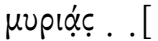

$\pi ! v \alpha$..[..].[ . $\bigotimes$

Source: $\Pi^{5 a}$ (fr. 3 col. ii) 1 beginning missing; probably separate poem from fr. 18

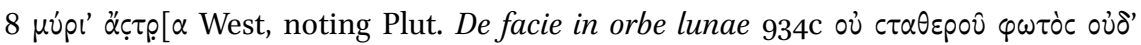

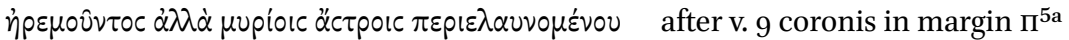

\footnotetext{
'Fragment 5'

$\bigotimes$

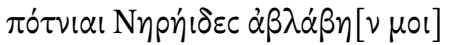

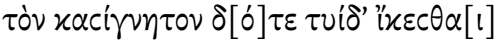

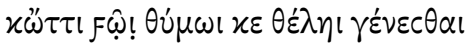

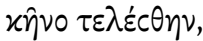

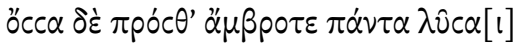

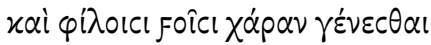

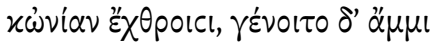

$\mu \eta \delta \alpha \mu \alpha \mu \eta \delta^{\prime}$ हiิ.

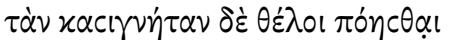

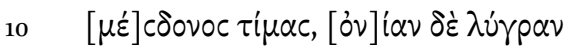

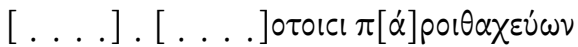

$[-\smile \smile-] . v \alpha$

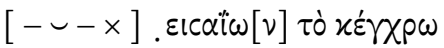

$[-\smile-] \lambda^{\prime} \varepsilon \dot{\varepsilon} \pi \gamma\left[\circ \rho^{\prime} i\right] \alpha \iota \pi 0 \lambda i \tau \alpha \nu$ 


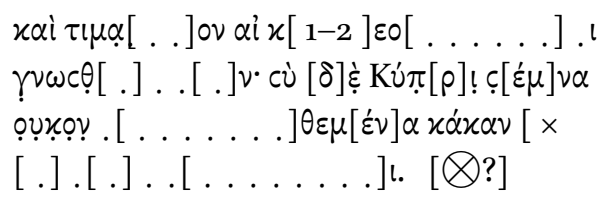

Sources: $\Pi^{3}, \Pi^{4}$ (fr. 6 ), $\Pi^{5 a}$ (fr. 3 col. ii) $1 \pi$ ó $v v$ lal (incipit in ' $\Pi^{\prime}$ ) $\Pi^{5 a}$ : [ $\left.\Pi^{4}\right]$, already pro-

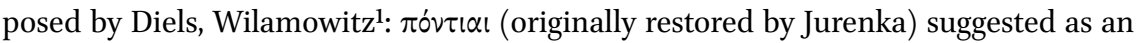
emendation by West comparing Pind. Pyth. 11.2, cf. also Pind. Nem. 5.36 $\alpha \beta \lambda \alpha \dot{\beta} \eta[\nu$

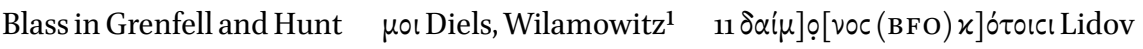

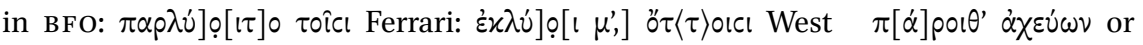

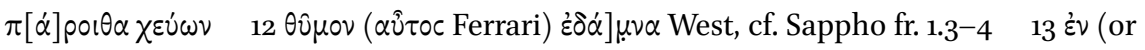

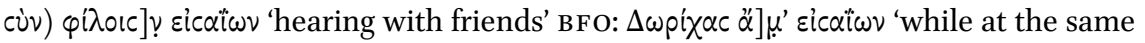

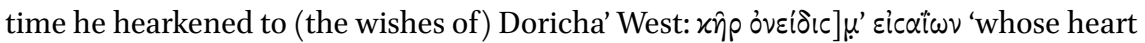

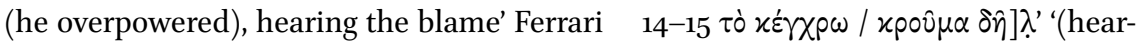

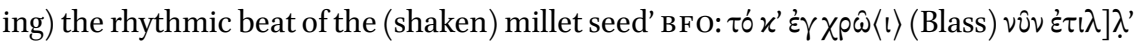

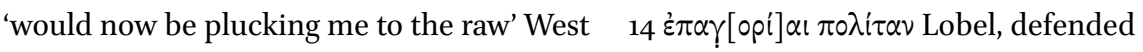
by West ('through the citizens' censure') or $\varepsilon \pi^{\prime}$ ' $\alpha \gamma\left[\varepsilon c^{i}\right] \alpha$ l 'at the leadership/command of

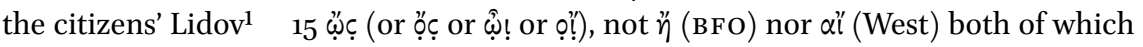

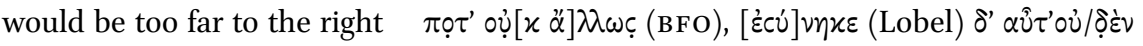
$\delta i \dot{\alpha}[\mu \dot{\alpha}] \varkappa \rho \omega$ B FO 'just as much as ever; but it was not long before he came to realize it';

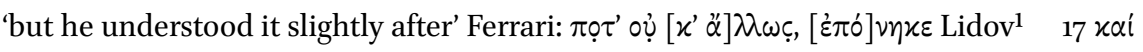

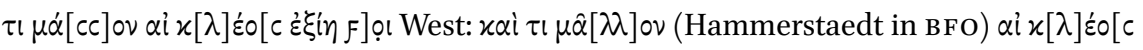

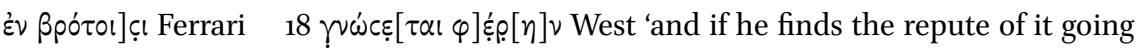

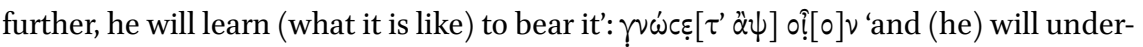
stand even more if again he realizes how much a good name counts among mortals'

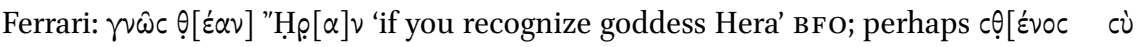

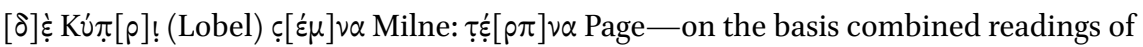
$\Pi^{3}$ and $\Pi^{4} \quad 19-20$ ợ $x$ ợ $\pi \dot{\alpha} \rho \mu 0]$ ! 'rendering an evil offense not unendurable (or: putting a stop to an unbearable evil), be persuaded by me' or (at end) 'remain by my side' Lidov in BFo: ợ

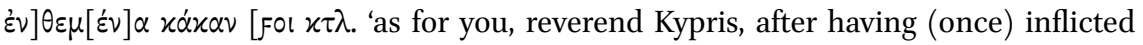
insupportable vice on him, [may you be merciful to us in the future]' West

\footnotetext{
'Fragment 9'

[Q]

$[\pi-(?)$

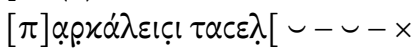




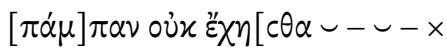

$[\mu] \alpha \hat{\tau} \varepsilon \rho$, żóp $\tau \alpha \nu .[$

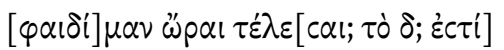

5

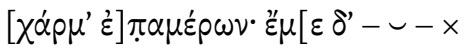

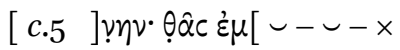

[ - ]ọv ärovcal[

[c.6 ]. $\nu \cdot \circ \hat{\tau} \tau \circ \circ \delta \varepsilon[\backsim-\smile-x$

$[-\smile] \eta \nu \dot{v} v \cdot \dot{\alpha} \beta \lambda \alpha[\beta \smile-\smile-x$

$10 \quad[-\smile] \alpha c \delta 1 \delta \omega \nu \cdot \pi \alpha[\smile-\smile-\times$

$[-\smile]$ óncev. [

$[c .6] \ldots . . .[$

$[c .5] \varepsilon \pi i x .[$

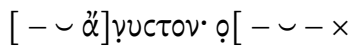

$15 \quad[-] \nu . \tau \varepsilon \lambda \varepsilon \dot{c} c \theta \eta$. [

$[-] \widehat{\rho}^{\prime}{ }^{\prime} \varepsilon \gamma \omega \pi \dot{\alpha} \mu \pi[\alpha \nu \cup \cup-\smile-\times$

$[-]^{\prime} . \chi \alpha v \gamma \lambda \omega \operatorname{\gamma ec} \alpha[\cup--\smile-x$

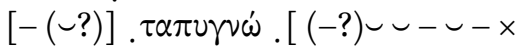

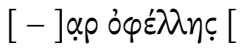

20

$[-] \varepsilon \rho \omega \nu \cdot \varepsilon . .[-\smile \smile-\smile-\times$

Sources: $\Pi^{3}$ (fr. 4), $\Pi^{5 a}$ (fr. 1 [but now to be placed after fr. 3]) incipit in ' $\Pi^{\prime}$ ? placement by West as the column preceding $\Pi^{5 b}$ is confirmed by continuities of fibers and patterns of damage; therefore the column following Sappho fr. $5 \quad 1-2 \Pi^{3}:\left[\begin{array}{ll}\Pi^{5 a} & 1\end{array}\right.$

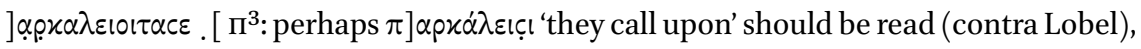

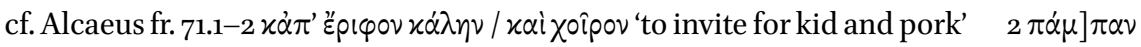
'completely' West ov่x है $\chi \eta[c \theta \alpha \pi \dot{\theta} \theta \varepsilon v \delta u v \alpha i \mu \alpha \nu$ 'do you not have the means with which

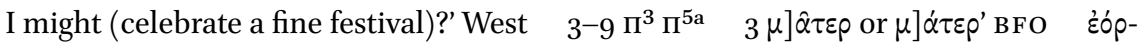
$\tau \alpha \nu$, cf. Sappho fr. 17.2 . . [ $\Pi^{5 a}$, apparent high point (punctuation) $4 \tau \varepsilon \dot{\lambda} \varepsilon[$ [cal 'celebrate' West, cf. Sappho fr. $1.27 \tau \varepsilon \dot{\varepsilon} \lambda \varepsilon c o v, 9.27$ below $\tau \varepsilon \lambda \varepsilon \dot{\varepsilon} \varepsilon \eta \eta$ (or perhaps $\tau \varepsilon \lambda \dot{\varepsilon}[\tau \omega \nu$ 'with the

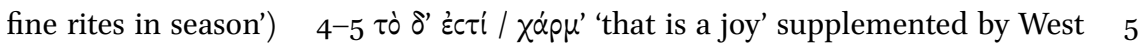
$\dot{\varepsilon}] \pi \alpha \mu \varepsilon \dot{\varepsilon} \omega \nu$ 'for us mortals who live for the day' S. Margheim in BFO; “"Those who live for the day" (or "for a day") must belong to a statement of a general truth, which Sappho

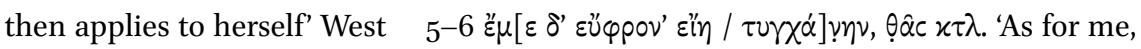
may I ever be cheerful, so long as' etc. West $6 \hat{\theta} \hat{\alpha} c$ with interlinear gloss $\varepsilon \omega c \zeta \omega\left[\right.$ in $\Pi^{3}$

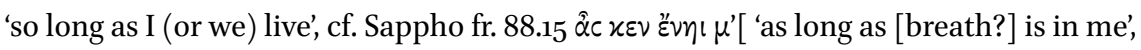


and $\theta \hat{\alpha} c$ with this meaning in Alcaeus $\alpha \mu\left[\Pi^{3}: \varepsilon \mu\left[\Pi^{5 a}\right.\right.$ ('a scribal error by dittography

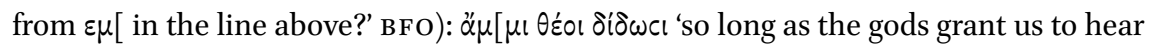

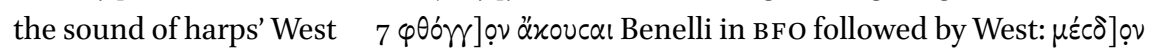

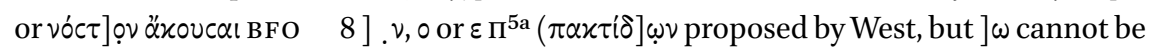
read) $9 \ddot{\alpha} \beta \lambda \alpha\left[\beta \varepsilon c\right.$ or $\dot{\alpha} \beta \lambda \dot{\alpha}\left[\beta \varepsilon c^{\prime}\right.$ Lardinois ( $\dot{\alpha} \beta \lambda \dot{\alpha}[\beta-$ BFO) cf. Sappho fr. 5.1, 84.7 $10-20$

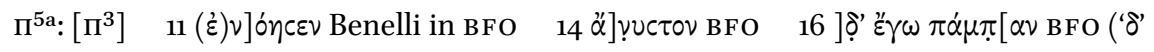
है $\gamma \omega$ in the previous line shows that Sappho is speaking of herself' West) 17 [ - ]'.

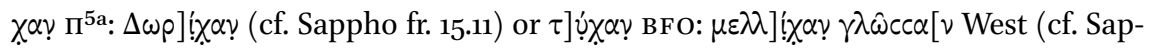
pho fr. 71.6 $\mu \varepsilon \lambda \chi_{\chi} \circ \varphi \omega \nu[)$ after v. 20, three verses and one or two stanzas are missing before incipit of Brothers Song which continued in $\Pi^{3}$ and $\Pi^{5 b}$

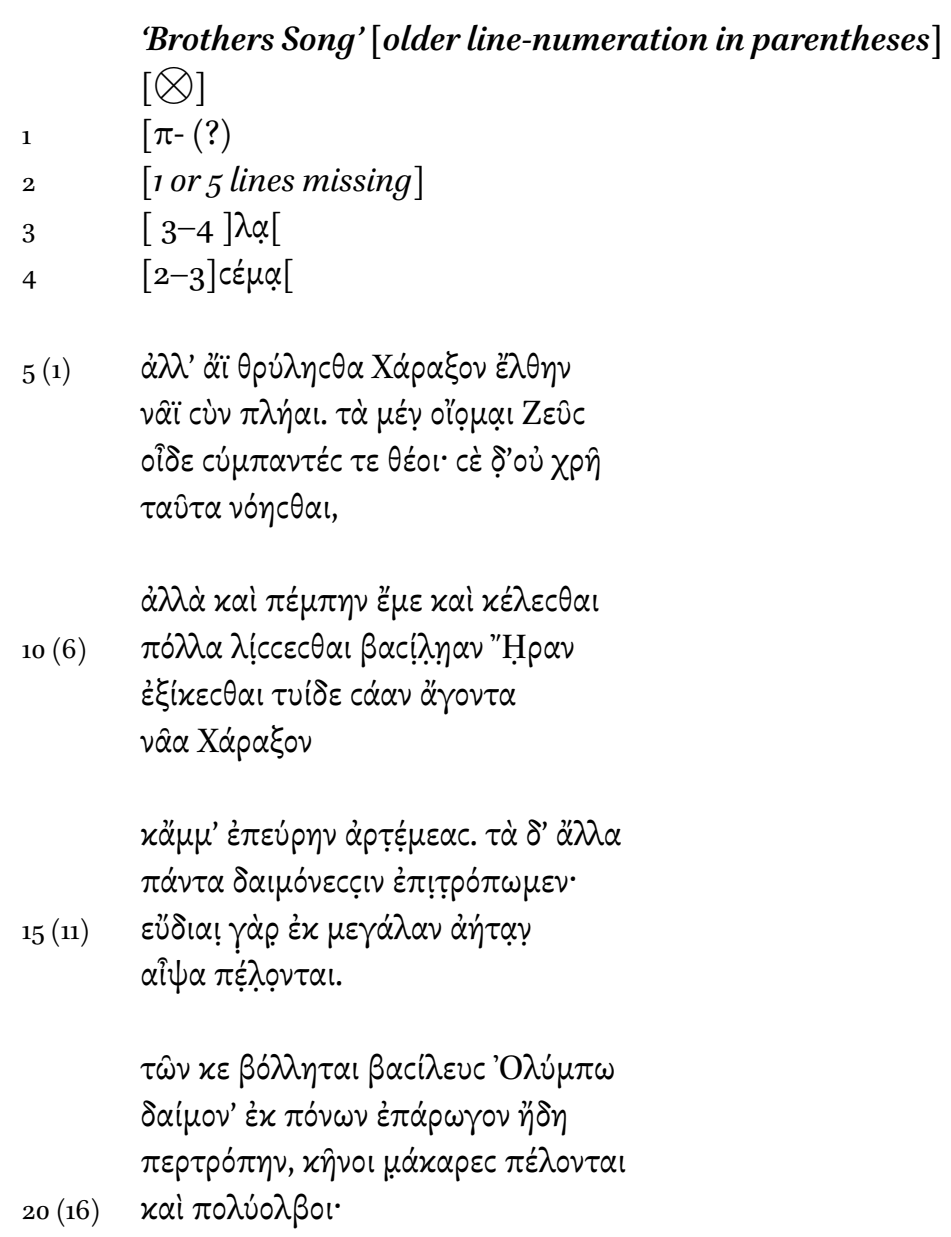




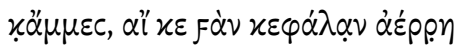

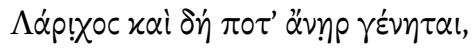

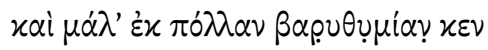

$24(20) \quad \alpha i \psi \alpha \lambda i \theta \varepsilon \varepsilon \mu \varepsilon v . \otimes$

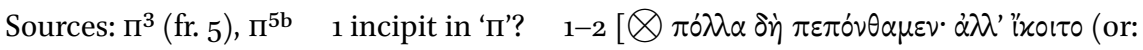

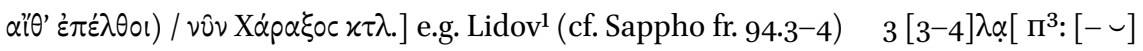
$\Lambda \alpha[\rho \vee \chi-O b b i n k: \pi \circ \lambda] \lambda \dot{\alpha}\left[\chi \circ L_{\text {Lidov }}^{1}\right.$ comparing Athen. 10.425a (= Sappho test. 203) $\pi \circ \lambda-$ $\lambda \alpha \chi 0 \hat{v}$ ('assuming that Athenaeus's source is a paraphrase or inference from an actual

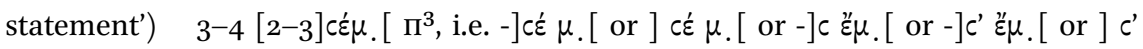

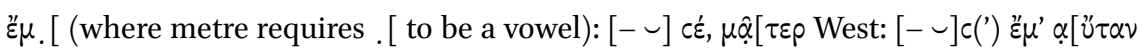

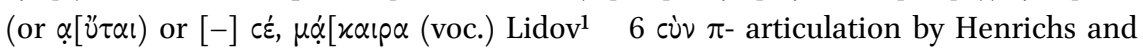

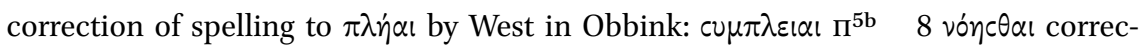

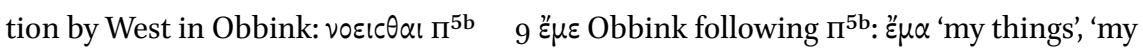
clothes' emendation by Bowie $\quad 11-13$ Od. 13.42-43 (Odysseus' wish to Alcinoos) $\alpha$ גú-

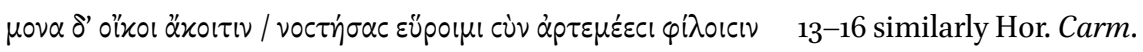
1.9.9-12, 3.29.32-34, cf. 43-45 (9 cetera $\left.=13 \tau \dot{\alpha} \delta^{\prime} \dot{\alpha} \lambda \lambda \alpha\right) \quad 13 \tau \dot{\alpha} \delta^{\prime} \dot{\alpha} \lambda \lambda \alpha$ Obbink following $\Pi^{5 b}: \tau \dot{\alpha} \delta^{\prime}$ ' $i \hat{i} \alpha$ emendation by Liberman p. 7 [8] 'but for all that is torment for us, let us trust it to the divine powers' $18 \dot{\varepsilon} \pi \dot{\alpha} \rho \omega \gamma o v$ correction in $\Pi^{5 b}$ by a second hand (cf.

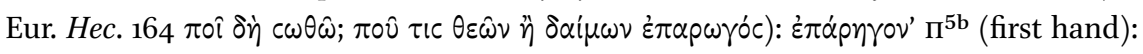

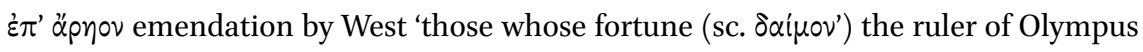

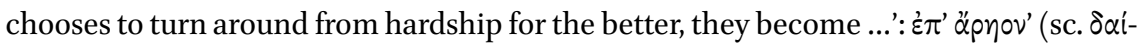
$\mu \nu^{\prime}$ ') emendation by Liberman pp. 7-8 [9] 'deflecting them away from misfortune to a better fate' 21 fà ${ }^{2}$ emendation by Lardinois (see Lobel, $A \mu \S 23$ pp. lxxxi-lxxxii and $\S 26$ pp. xci-xciv, esp. xci-xcii): $\tau \dot{\alpha} \nu$ Obbink following $\Pi^{5 b}$ after v. 24 coronis in margin $\Pi^{5 b}$

\section{'Kypris Song'}

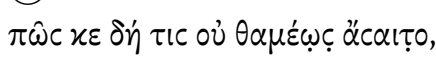

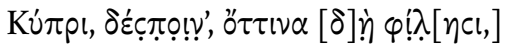

[

$[\pi \circ \hat{\imath}]$ ov ${ }^{2} \times \eta \subset \theta \alpha$

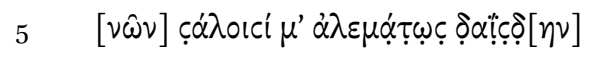

$\left[i \mu \varepsilon^{\prime}\right] \rho \omega\langle\iota\rangle \lambda \dot{v}\{\imath\} c \alpha \nu \tau \iota$ Үó $v^{\prime} \omega \mu \varepsilon-[\mathrm{x}$

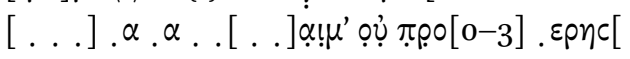

$[-\smile] \nu \varepsilon \underline{\varepsilon \rho} .[.] \alpha !$ 


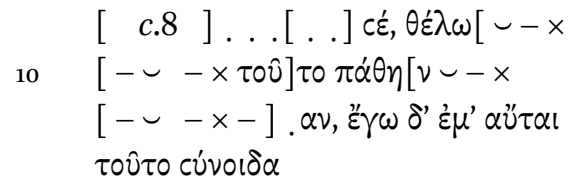

$$
\begin{aligned}
& c .13] .[.] . \tau 0 \mathrm{~T}[\ldots . .] . \\
& c .13] \operatorname{sv\alpha \mu }[ \\
& \text { ].[.].[ } \\
& c .12]
\end{aligned}
$$

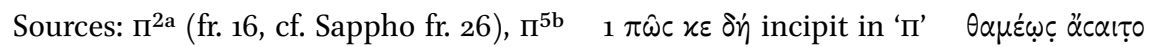

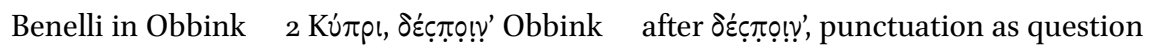

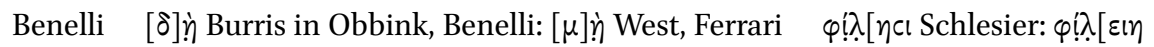
Burris in Obbink: $\varphi$ ! $\lambda[\eta \subset \theta \alpha$ West, Ferrari, Benelli $3 x \omega \nu$ ] Prodi (anaphoric of ov in v. 1): $x \dot{\omega} c]$ ] West $x \alpha i]$ Obbink (2014b) or $x \alpha i$ (= xai $\varepsilon i)]$ Benelli and $\dot{\omega} c]$ Ferrari are slightly too short for the space $\pi \dot{\alpha} \theta \alpha \underline{\nu}$ (gen. pl. of Pindaric $\pi \dot{\alpha} \theta \alpha$ ) or $\pi \dot{\alpha} \theta \alpha c \chi^{\prime} \alpha \underline{\lambda}[\alpha c c \alpha$ l

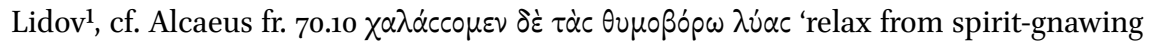

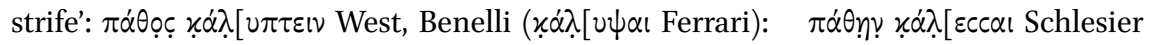
$\pi \alpha \theta$ - confirmed by multi-spectral imaging, not $\pi \alpha \lambda$-; end $\chi \alpha \lambda$ [ or $x \alpha \lambda$ [ end of v. 3 ,

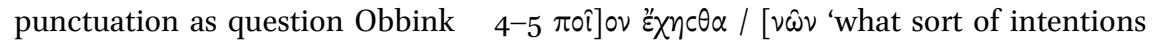

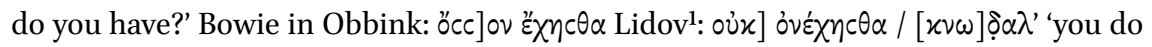
not hold back the mordacious pests' West: ov่x] obvé $\eta c \theta \alpha$ (after which end of sentence)

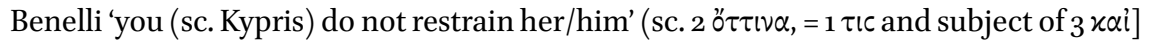
$\theta \dot{\varepsilon} \lambda$ ol) i.e. from the sufferings of love' or 'you do not keep under control her/his erotic drives' end of v. 4, punctuation as question Ferrari 5 бó $\lambda$ oı ı Hammerstaedt in

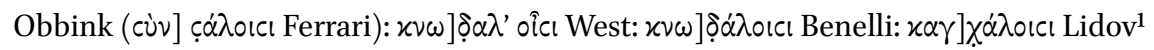

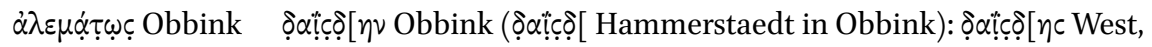
Ferrari, Benelli end of v. 5, punctuation as question West $6 i \mu \dot{\varepsilon}] \rho \omega\langle\imath\rangle$ Obbink,

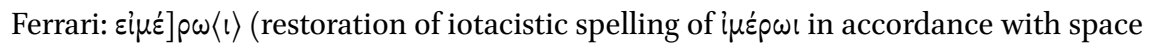
in $\left.\Pi^{5 a}\right)$ West: $\left.x i \mu \varepsilon \dot{\varepsilon}\right] \rho \omega\langle\iota\rangle$ Benelli: $\left.\mu \eta^{\prime} \mu^{\prime} \varepsilon^{\prime}\right] \rho \omega\langle\iota\rangle$ West $\lambda \nu^{\prime}\{!\} c \alpha \nu \tau \iota$ Obbink, Ferrari, Benelli:

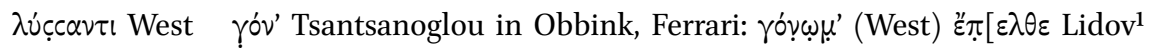

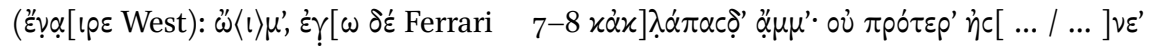
$\varepsilon \rho \alpha[$ [ic] $\alpha$ ! 'do not despoil me with raging love and devastate us. You were not previously ... to me when I was in love' West: $\lambda \alpha i] \lambda \alpha \pi \alpha c[\varphi] \alpha \hat{i} \mu^{\prime}$ (Tsantsanoglou) ov $\pi \rho \circ[\tau o ́ v o r c]$ $\pi \varepsilon \rho \eta \dot{c}[\eta \nu$ 'alas, but I believe that the gusts will not overcome the stays' Ferrari 8

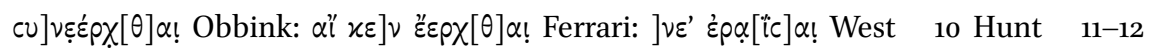
supplied from Apollonius Dyscolus Pron. 1.51.1ff. Schneider (formerly Sappho fr. 26) where the poem ends (and the next begins) is uncertain 


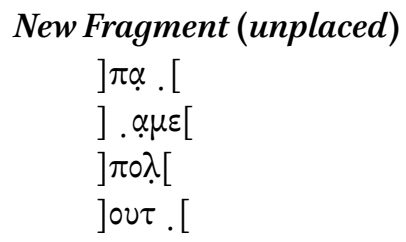

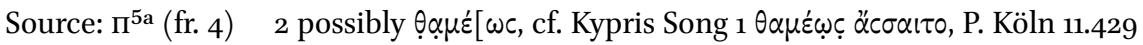

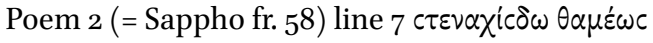

\section{Translations}

\section{'Fragment 15'}

[... ] blessed goddess

[... ] (may he?) give atonement for previous mistakes

[... ] with fair fortune (reach?) harbor

$[\ldots]$,

Kypris, and may (she?) find you [the cruelest], And may she, Doricha, not boast, telling of how he came a second time for a longed-for desire.

\section{'Fragment 16 '}

There are those who say of a host of cavalry, some of foot-soldiers, while others say of ships to be the fairest thing on the black earth. But I: whatsoever someone desires.

It is altogether simple to make this clearly known to all: Helen, by far outstanding in beauty of mortals, who had a husband, the best of all men,

left him behind, and, sailing, travelled to Troy and without any thought at all for her dear child or her parents either; but [Kypris?] led her off-course $[\ldots]$ 
for [she (sc. Kypris?) with un] bending mind accomplishes?] easily [whatever she] thinks; [which] now puts me in mind of Anaktoria gone away though she is.

Sooner would I watch her desirable gait and bright glow of her face than all the chariots of Lydia and soldiers in arms. $\otimes$ ?

\section{'Fragment 16a' $\otimes$ ? \\ It is not possible for a human being to be completely fortunate; but one may pray to enjoy a share of happiness. This I know for myself.}

[2-4 stanzas missing]

$$
\text { ... ] to be }
$$

...] you walked on tip-toes

...] on the snow. But she many things with $[\ldots \quad]$

$$
\begin{aligned}
& \text {...] being }[\ldots] \text { to depart } \\
& \text {... ]. For whomsoever }
\end{aligned}
$$

I treat favorably, those most of all harm me without warning. $\otimes$

\footnotetext{
'Fragment 17'

$\bigotimes$

Near here, indeed, [... let be celebrated] your [charming] festival, revered Hera, which the Kings, the Atreidai, established on a vow,
}

since they had accomplished heroic exploits in the beginning at Troy, but later on putting in just here: for they could not find their way 
before they had approached you, and Suppliant Zeus and Thyone's soothing child.

Now we, too, [continue] to perform [these things] just like of o[ld]

that are pure and of high[est. For a huge] throng of unmarried women and wives [gather right here] around [your altar, piously wishing to sing in] measures the sacr[ed cry.]

Each $[\ldots$

$[\cdots$ to be $[\ldots$

[He]ra, to come back. $\otimes$

'Fragment 18'

Every $[\ldots]$ would $[\ldots$

to narrate $[\ldots$

$\mathrm{m}[\mathrm{y}]$ tongue $[\ldots$

to weave wild tales $[\ldots$

and a husband [...] the best things

greater yet $[$ than ...

[two verses missing]

mind $[\ldots$

[three verses missing]

[traces of six more lines + 4-6 stanzas missing, some belonging to Fragment 18a]

\section{'Fragment 18a'}

$[\ldots]$

Since even $[\ldots$

lacking the season $[\ldots$

both night and $[\ldots$ 
thousands of st[ars

drin[k?] $\otimes$

\section{'Fragment 5 '}

Revered daughters of the sea god, grant that [my] brother may arrive here unharmed and whatsoever he should desire in his mind let that be completed.

And as much as he has previously done wrong, that he atone for it all; that he be a pleasure to friends, and a harm to enemies - then may we never have any.

And may he want to put his sister in a position of greater honor, since before he was suffering cruel agony at the hands of $[\ldots]$

$[\cdots$

$[\ldots]$ hearing the $[\ldots]$ of the millet seed

[... bu]t through the citizens' censure as is ever the case, and on the other hand he realized it not long after.

And $[\ldots]$ if $f[a m]$ e $[\ldots$ know [...]. But you, hallowed Kypris, After an unendurable evil, [give ...] $[\ldots] \otimes$ ?

Fragment 9 (P. GC inv. 105 fr. 1)

[Q]

$[\mathrm{P}-\ldots(?)$

they are inviting us over for [...]

Do you not have all [that we need,

Mother, for the festival? 
[splen]didly and in season to cele[brate? It is this, which [is a joy] for mortals who live for the day. As for $\mathrm{m}[\mathrm{e}$, [may I ever ...], as long as to $\mathrm{m}$ [e it is allowed

$[\ldots]$ to hear.

$[\ldots]$. And this $[\ldots$

[...] now. Unhar[med ...

$[\ldots]$ while giving. $[\ldots$

[she th] ought.

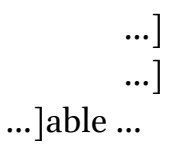

$[\ldots]$... to have been completed.

[...]. But I entirely $[\ldots$

$[\ldots]$ tongue $[\ldots$

$[\ldots]$ despair $[\ldots$

[... f] or you ought. $\otimes$ ? (or one stanza missing)

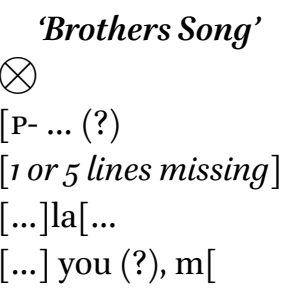

But you are always chattering for Charaxos to come with a full ship. Zeus and all the other gods, know these things, I think. But it is not necessary for you to think these things.

Summon me instead and commission me to beseech Queen Hera over and over again that Charaxos may arrive, piloting back here a ship that is safe,

and find us safe and sound. Let us entrust all other things to the gods: for out of huge gales fair weather swiftly ensues. 
All of those whom the King of Olympus wishes a divinity as helper to now turn them from troubles, become happy and richly blessed.

And if Larichos lifts up his head, if only he might one day be an established man, the deep and dreary draggings of our soul we'd swiftly lift to joy. $\otimes$

\section{'Kypris Song' $\otimes$}

How can someone not be hurt and hurt again, Kypris, Queen, whomsoever one really loves, and not especially want respite from suffering? What sort of thoughts do you have

to pierce me idly with shiverings out of desire that loosens the knees [...] $[\ldots] \operatorname{not}[\ldots$ $[\ldots] \ldots$

$[\ldots]$ you, I wish $[\ldots$

$[\ldots]$ to suffer this $[\ldots$

[...]. This

I know for myself.

New Fragment (unplaced)

$[\ldots] \ldots[$

$[\ldots]$ frequen[tly?

$[\ldots] \ldots[$

$[\ldots] \ldots[$ 